\title{
Pygmy Rabbit Surveys and Habitat Modeling
}

\author{
A Progress Report prepared for \\ Bureau of Land Management \\ Montana State Office \\ Dillon Field Office \\ 1005 Selway Drive \\ Dillon, Montana 59725-9431 \\ Task Order \#23 \\ Assistance Agreement \#ESA 010009
}

\author{
Submitted by \\ Susan Lenard, Coburn Currier, and Paul Hendricks
}

\author{
Montana Natural Heritage Program \\ Natural Resources Information System \\ Montana State Library \\ P.O. Box 201800 \\ 1515 East Sixth Avenue \\ Helena, Montana 59620-1800
}

March 2004 
A field survey was performed the first week of March 2004 for the Dillon field office of the Bureau of Land Management to assess current pygmy rabbit activity in southwestern Montana. The purpose of the fieldwork was to survey locations with documented historic pygmy rabbit (Bracbylagus idaboensis) activity and to test a predictive model for pygmy rabbit presence. Known areas of use were derived from the Point Observation Database (POD) housed at the Montana Natural Heritage Program. The majority of information known on historic locations comes from the field survey work of Ryan Rauscher (Montana Department of Fish, Wildlife, \& Parks) during 1996 and 1997, with a collection of records from Chuck Bowey (US Forest Service-Beaverhead National Forest) during those same years. Pygmy rabbit burrow activity was described as either active (current use) or inactive (recent or historic [old] use). Global Positioning Unit (GPS) point locations were available to approximate locations of burrows discovered during the 1996-97 survey efforts.

The project is designed to survey a subsample of the known locations with efforts focused on BLM, Forest Service, or state land parcels. Therefore, all known points from the POD were overlain on a landownership map with all private lands excluded from the 2004 field survey plans. The historic locations of Horse Prairie, Medicine Lodge Creek (south of Ayers Canyon), Badger Gulch/Sagebrush Creek, and Upper Ermont Creek were inaccessible due to deep snow. Additionally, an attempt was made to access areas east of Interstate-15, but none of these areas were ultimately surveyed as a result of inaccessibility and/or focused efforts at other locations.

The second component of this project, the application of a predictive model for pygmy rabbits, was tested (see corresponding discussion section). Additionally, we elected to include another component to the fieldwork. This activity involved surveying new areas, those without documented historical use, to gain a better understanding of the extent of pygmy rabbit distribution. The sites selected contained a vegetative cover of big sagebrush and other landscape features similar to those observed at locations of known activity.

Three members of the Montana Natural Heritage Program staff performed the five days of field survey. The methods employed to survey sites generally involved walking zig-zag loop transects in an attempt to cover the most ground in the shortest amount of time. Pygmy rabbit presence was confirmed by the presence of burrows, scat (brown indicated current "active" use; grey indicated recent "inactive" use; "very grey" indicated old), sagebrush floret clippings, tracks, and on the rare occasion, observation of individual rabbits. When burrows were located they were recorded on GPS units and evidence of activity was noted.

In the following description of sites, a burrow may represent multiple holes and more accurately may be called a burrow system. Each of the burrows ranged from one to, on one occasion, nine holes. A general distance of 30 meters was used as an estimate to distinguish between individual burrow systems. One hundred ninety-eight burrow systems were recorded, representing a total of 380 burrow entrances. Of this total, 231 were associated with current pygmy rabbit activity. The higher proportion of active to inactive burrows is more likely a result of the fact that burrows with current activity are much easier to locate (tracks it the snow make them highly apparent). The relative difference in abundance should not necessarily be taken to be indicative of any level of past versus current activity.

\section{Surveys of Historic Locations}

Five historic locations of pygmy rabbit use were surveyed for presence of burrows: Grasshopper Creek, Bannack area, Sheep Corral Gulch, south end of Clark Canyon Reservoir, and Lime Kiln 
Gulch. The most extensive searches occurred at the south end of Clark Canyon Reservoir and Lime Kiln Gulch.

[See attached map for general point locations (Figure 1). Historic burrow locations are indicated by orange dots. Burrows observed during the March 2004 field survey ate indicated by red, blue, or yellow; see legend for description].

South end of Clark Canyon [T10S R10W S30]: Active and inactive burrows were observed. Of the 22 burrows discovered at this location, four were recorded as active; ten showed signs of recent activity, two were identified as old; and six burrows were recorded as possible, but unconfirmed, pygmy rabbit burrows.

Lime Kiln Gulch [T11S R10W S5 \& S6; T10S R10W S32]: No active pygmy rabbit burrows were found. Of the four openings observed, only one was considered a recent pygmy rabbit burrow (grey pellets nearby). Because of the absence of pellets at the other three openings, they were recorded as possible burrows, but unconfirmed.

Grasshopper Creek [T7S R12W S9]: Fourteen burrows were observed, and all were active with signs of fresh tracks, scat, urine stains, and fresh sagebrush clippings.

Sheep Corral Gulch (east of Badger Gulch) [T9S R12W S10 \& S3]: Twenty-two burrows were observed, 14 were classified as active, four as recent, two as old, and two as undetermined (whether active or inactive).

Bannack Area north [T8S R12W S11]: Seven active burrows were observed. Fresh tracks, scat, and sagebrush clippings were evident at each burrow system. A survey within the town of Bannack, where an historical burrow had been recorded, revealed no evidence of current pygmy rabbit use.

Bannack Area south [T8S R12W S22]: Five active burrows were recorded at this site. Fresh tracks, scat, and sagebrush clippings were evident.

\section{Surveys of Areas Without Activity Previously Recorded}

Seven new areas were surveyed following the same protocol as sites with documented historical use. These locations were selected because of their similar appearance to sites with known pygmy rabbit activity. All of these locations revealed current pygmy rabbit use and deserve further investigation. A portion of the fall field visit may include more focused efforts at one or more of these locations.

Ermont Area BLM [T7S R10W S6]: Surveys of the Ermont area occurred further east and south of the historically recorded observations, and revealed ten active burrows and two old ones.

Ermont Area State Section [T7S R10W S16]: Six burrows were recorded on this state section; two of which were active, three recent, and one old.

Coyote Flats [T7S R10W S16]: Twenty-eight burrows were recorded in this area. Of these, 14 showed signs of current activity; ten were recorded as recent, three as old, and one as undetermined.

Coyote Creek [T9S R13W S32]: A total of 21 burrows were tecorded, 19 of which were active. Evidence of activity included fresh tracks, pellets, and sage clippings. Two burrows were described as having recent activity. This area was particularly active and evidence suggested multiple entry 
holes per burrow system. One system appeared to have 9 holes (all within 12 meters) and all holes showed current activity.

Medicine Lodge Creek - Kissick Gulch [T11S R12W S11, S12, S13, S14, S36]: Twenty-two burrows were recorded; nine were identified as active; nine as having recent activity; and four undetermined.

Medicine Lodge Creek - Keystone Gulch (state section) [T11S R12W S36]: Thirteen burrows were identified in this area. Of the total, four were active, and the remaining ones were identified as either old or undetermined.

Rape Creek [T10S R13W S1\& S2]: Twenty-three burrows were identified. Of this total, ten were active, three recent and ten were old. Evidence at this site included fresh tracks, scat, and sage clippings.

\section{Application and Testing of Pygmy Rabbit Predictive Model}

Two models predicting pygmy rabbit distribution are known, one developed in Idaho, the other in Wyoming. The Wyoming model was not available for application during the preparation of this project but efforts are currently underway to obtain a document describing this model.

The Idaho model was applied to areas within the known distribution of pygmy rabbits in southwestern Montana. The model utilizes the following attributes: soil depth, average percent clay, elevation, slope, and canopy cover of big sagebrush (Artemisia tridentata). Application of the model across southwestern Montana was limited to Madison County as soil maps for Beaverhead County, from the Natural Resources and Conservation Service (NRCS), are not yet available. This limited application of the model across the greatest area of known distribution. The BLM biologist in charge of this project compared the resulting limited model's predicted range with his personal field knowledge and deemed the model non-functional as an accurate predictor of pygmy rabbit distribution. Thus, during this week of surveys, no sites predicted in this initial application of the model were field-truthed.

The biologist requested that Heritage staff obtain draft soils maps for Beaverhead County from the NRCS, if available, and apply either of the known models to test for accuracy during a field survey in the fall of 2004.

\section{Conclusion}

Plans for the fall 2004 visit include field-testing at least one of the two predictive models applied across Beaverhead County and visiting historic locations not surveyed in March 2004.

Additionally, most of the sites indicating pygmy rabbit presence appear as fairly distinct isolated patches. It is unclear if this is a product of search effort or environmental constraints. We tentatively plan to select a location with current activity discovered during the March 2004 survey and describe the full extent of pygmy rabbit use within that particular site. This approach may help to identify connectivity between locations appearing discrete as well as characteristics of the landscape defining the limits of a particular local population. Selection of the site may serve a dual purpose as it may also provide the opportunity to field-test the predictive model at this location. 


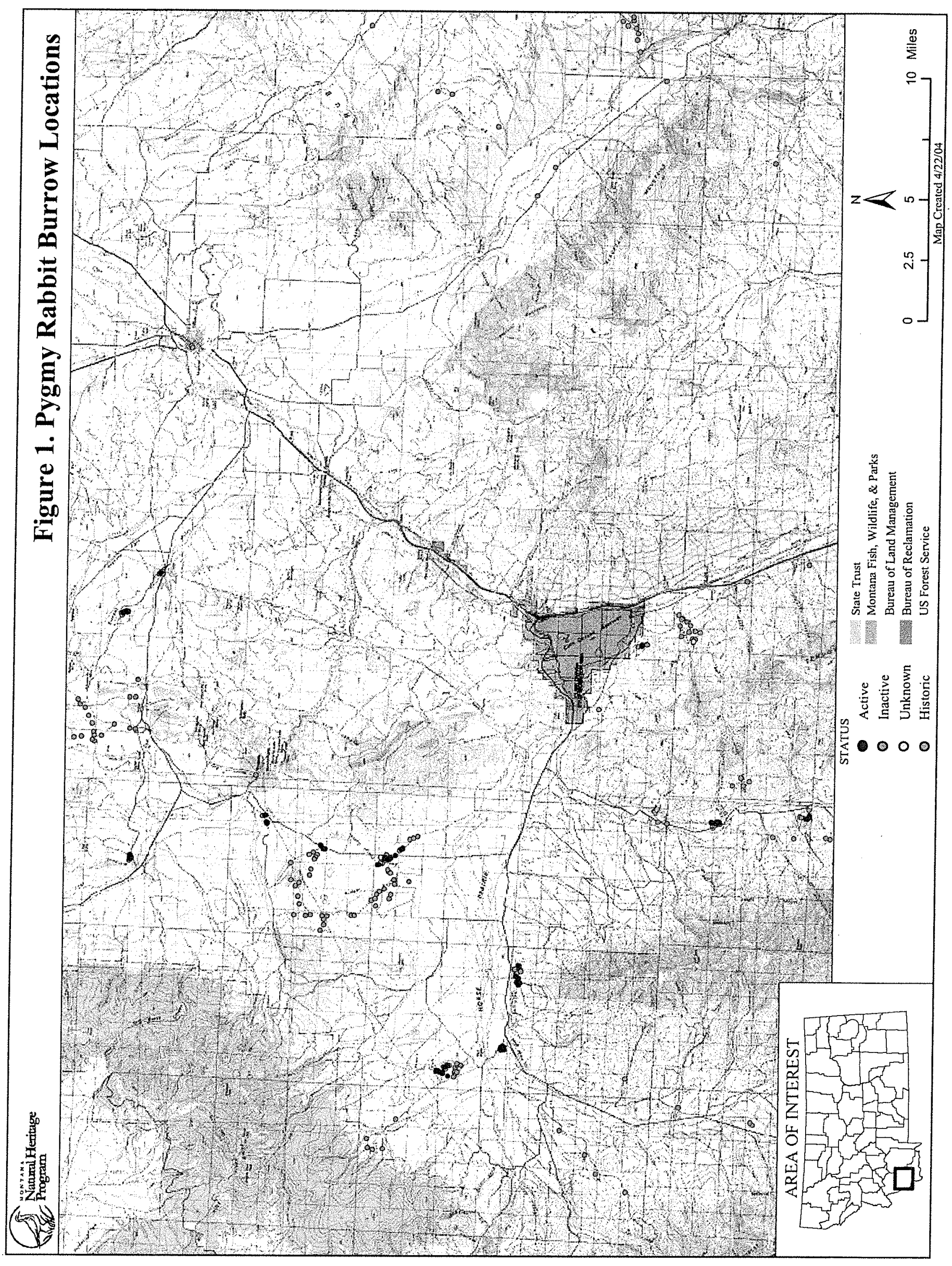

